\title{
Omnivory and grazer functional composition moderate cascading trophic effects in experimental Fucus vesiculosus habitats
}

\author{
Britas Klemens Eriksson - Christiaan van Sluis • \\ Katrin Sieben • Lena Kautsky • Sonja Råberg
}

Received: 24 August 2010/Accepted: 29 November 2010/Published online: 18 December 2010

(C) The Author(s) 2010. This article is published with open access at Springerlink.com

\begin{abstract}
We tested the relative strength of direct versus indirect effects of an aquatic omnivore depending on the functional composition of grazers by manipulating the presence of gastropod and amphipod grazers and omnivorous shrimp in outdoor mesocosms. By selectively preying upon amphipods and reducing their abundance by $70-80 \%$, omnivorous shrimp favoured the dominance of gastropods. While gastropods were the main microalgal grazers, amphipods controlled macroalgal biomass in the experiment. However, strong predation on the amphipod by the shrimp had no significant indirect effects on macroalgal biomass, indicating that when amphipod abundances declined, complementary feeding by the omnivore on macroalgae may have suppressed a trophic cascade. Accordingly, in the absence of amphipods, the shrimp grazed significantly on green algae and thereby suppressed the diversity of the macroalgal community. Our experiment demonstrates direct consumer effects by an omnivore on both the grazer and producer trophic levels in an aquatic food web, regulated by prey availability.
\end{abstract}

Communicated by S. D. Connell.

Electronic supplementary material The online version of this article (doi:10.1007/s00227-010-1602-6) contains supplementary material, which is available to authorized users.

B. K. Eriksson $(\varangle) \cdot$ C. van Sluis $\cdot$ K. Sieben

Department of Marine Benthic Ecology and Evolution,

Centre for Ecological and Evolutionary Studies,

University of Groningen, P.O. Box 11103 ,

9700 CC Groningen, The Netherlands

e-mail: b.d.h.k.eriksson@ rug.nl

L. Kautsky · S. Råberg

Department of Botany, University of Stockholm,

10691 Stockholm, Sweden

\section{Introduction}

Declines in marine top-predators and subsequent increases in mesopredators, including both medium-sized fish and crustaceans, are a global phenomenon that have shifted the trophic structure of many benthic and pelagic systems (Worm and Myers 2003; Daskalov et al. 2007; Myers et al. 2007; Casini et al. 2008; Eriksson et al. 2009). Such marine mesopredator release events may generate decreases in grazers/herbivores and cascading increases in primary producers (Scheffer et al. 2005; Vasas et al. 2007; Heithaus et al. 2008). However, this often assumes strong predator prey interactions over discrete trophic levels, while many mesopredators are omnivores that consume both secondary and primary producers and thereby can act both as mesopredators and grazers. Thus, there is an urgent need to document the different roles of omnivores in aquatic food webs to predict effects of changes in higher trophic levels.

Current interpretations of food web dynamics strongly indicate that omnivory-feeding on more than one trophic level—can stabilize complex food webs (Polis and Strong 1996; Fagan 1997; McCann et al. 1998; Neutel et al. 2002). The stabilizing effect of omnivory is supported by ecological models and mathematical analyses of real food webs, both of which show that omnivores dampen strong synchronous fluctuations in population sizes by introducing many weak trophic links (McCann et al. 1998; Neutel et al. 2002). As an increase in the number of trophic links dilute direct effects of single-species groups through the food web (Polis and Strong 1996), experimental food webs with a higher degree of omnivory are less sensitive to disturbances (Fagan 1997).

The contribution of omnivores to predator guilds, therefore, is important in determining how effects of species loss at higher trophic levels cascade down the food 
web (Polis and Strong 1996; Duffy et al. 2007). Declines in apex predators can generate trophic cascades, whereby concomitant increases in mesopredator communities indirectly favour primary producers (e.g. Frank et al. 2005; Casini et al. 2008; Eriksson et al. 2009). Increased omnivory in the mesopredator trophic level may weaken trophic cascades, because omnivores may produce opposing direct and indirect impacts on lower trophic levels (Polis and Strong 1996; Pace et al. 1999; Ho and Pennings 2008). For example, omnivores that feed both on animals and plants/ algae may decrease the strength of trophic cascades from predators to primary producers, by switching to grazing when herbivore abundances decline. This was demonstrated in a rocky shore mesocosm experiment, where strong trophic cascades triggered by carnivorous predators were dampened when omnivores were added to the experiments (Bruno and O'Connor 2005). Thus, omnivores may stabilize food webs exposed to loss of apex predators by preventing mesopredator-release events from cascading down the food web. However, by being less dependent on fluctuations in one single prey population, omnivores can survive on alternative foods when the preferred prey is scarce and thereby exert more persistent top-down control (Polis and Strong 1996). Omnivores also have simultaneous direct negative effects both on consumers and producers since they can act both as predators and grazers (Diehl 1993; Ho and Pennings 2008), indicating that increases in omnivore populations may have even stronger vertical effects on food webs than carnivores. Thus, because of the interplay between direct consumption and indirect positive effects, net trophic effects of omnivores are difficult to predict and probably highly dependent on prey community composition.

The aim of this study was to test the relative strength of direct versus indirect effects of an omnivorous shrimp, Palaemon elegans, depending on prey composition in a three-step benthic food web created in mesocosms using invertebrate grazers and algae from the Baltic Sea (Fig. 1). Palaemon spp. feed significantly on both crustacean mesograzers (small and mobile peracarid crustacean herbivores such as amphipods and isopods) and filamentous macroalgae (Matthiessen et al. 2007; Jephson et al. 2008; Persson et al. 2008). In the same study system, Råberg et al. (2007b) demonstrated that the functional composition of this grazer community determines algal community composition: gastropods control microalgal production and crustacean mesograzers mainly control macroalgal production. In the present experiment, we specifically test how omnivore effects interact with grazer identity, by manipulating the presence of the omnivore and the functional groups of grazers. We hypothesized that omnivore predation in our study system generates stronger direct than indirect effects on the algal community. Thus, that

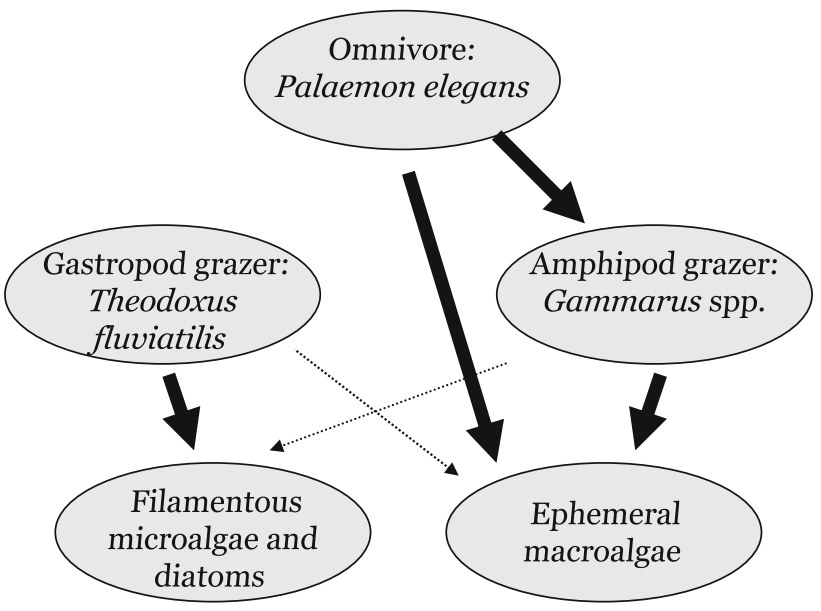

Fig. 1 Experimental food web. Arrows show the relative importance of feeding relations, based on (Matthiessen et al. 2007; Råberg and Kautsky 2007b; Jephson et al. 2008; Persson et al. 2008)

Palaemon does not induce a trophic cascade by reducing the grazers, but instead may compensate for declining abundances of grazer prey by significantly consuming both the grazer and algal trophic levels.

\section{Materials and methods}

We conducted the mesocosm experiment at the Askö Laboratory $\left(58^{\circ} 49^{\prime} \mathrm{N}, 19^{\circ} 39^{\prime} \mathrm{E}\right)$ in the western Baltic Sea from 4 July to 4 August 2008. The Baltic Sea is brackish with minimal tides, and the only large, habitat-forming, perennial algae growing in the study area is Fucus vesiculosus (hereafter Fucus). In this experiment, we studied the ephemeral micro- and macroalgae and invertebrate community associated with Fucus, while Fucus itself was used as foundation habitat only. Palaemon elegans (hereafter Palaemon) was the dominant invertebrate omnivore in the area (Råberg and Kautsky 2007a). Isotope analyses suggest that it mainly consumes amphipods/isopods or ephemeral macroalgae, depending on the structure of the prey community (Jephson et al. 2008). The short-lived ( $\sim 1$ year) amphipod Gammarus spp. (hereafter Gammarus) was the most common crustacean grazer found in the community associated with Fucus. Gammarus reproduces continuously from spring to autumn and eggs hatch within 5-15 days (Kinne 1960). Because of its rapid reproduction, Gammarus should respond to changes in producer abundance (indicative of a 'dynamic' grazer) (Gruner et al. 2008). The snail Theodoxus fluviatilis (hereafter Theodoxus) was the most common gastropod in the area (Råberg and Kautsky 2007a). It is comparably longer-lived (2-3 years), and as eggs need approximately 3 months to hatch (Kirkegaard 2006), population sizes are likely to change more slowly (static) than 
Gammarus. Epiphytes on Fucus are dominated by a mix of ephemeral cyanobacteria, microalgae (mainly diatoms and uniseriate green algae) and macroalgae (brown, green and red branched filamentous or sheet-like algae).

Specimens of Fucus of similar size and appearance were collected from the same area near the laboratory at a depth of $0.5 \mathrm{~m}$. After removing visible fauna by hand, Fucus thalli were anchored to separate bricks with plastic ties and placed together for 5 days in a holding tank. By placing all Fucus thalli together, we allowed for exchange of invertebrate fauna between the thalli. Since all fauna cannot be removed from the Fucus thallus without a strong mechanical disturbance, this was important to homogenize the background start-up community in the experiment. Each thallus weighed $\sim 300 \mathrm{~g}$ wet mass and had no visible epiphytes.

At the start of the experiment, one Fucus brick was randomly extracted from the common holding tank and placed in each of 40 circular, 30-1 plastic containers (the mesocosms) standing outside and near to the shore. Although we specifically selected Fucus thalli that were free from visible epiphytic growth for the experiments, natural Fucus individuals frequently harbour a rich flora of microscopic propagules of ephemeral micro- and macroalgae. This propagule bank enhances growth of filamentous algae many times compared to sterile artificial substrates (Lotze et al. 2001; Eriksson et al. 2006). We utilized the propagule bank to get a faster response of the algal community in the mesocosms. Fucus is also a natural habitat for the invertebrate fauna in the area, promoting natural behaviour in the mesocosms. The cylindrical containers were supplied with a constant flow (ca. $11 / \mathrm{min}$ ) of sandfiltered seawater pumped from the shore near the laboratory. Salinity and water temperature inside the containers were 6.9 (PSU) and $18^{\circ} \pm 2^{\circ} \mathrm{C}$ (observations at 14:00; maximum temperature in any container $19.8^{\circ} \mathrm{C}$; air temperature of $27^{\circ} \mathrm{C}$ ), respectively, corresponding to the natural conditions measured at the field station (unpublished data).

The experiment was designed as a factorial test of omnivore presence or absence (2 levels) and a simple diversity gradient in grazer community composition (4 levels), with 5 replicates per treatment placed in a randomized block design (40 mesocosms). For the omnivore treatment, we added three individuals of Palaemon (total body length $=40-50 \mathrm{~mm}$ ) to half of the containers, which corresponded to the average number found per Fucus thallus in the field (unpublished data). To each omnivore treatment (no omnivore/omnivore present), four different grazer treatments were applied: (1) no grazers, (2) 500 individuals of the gastropod Theodoxus in a single-species assemblage, (3) 50 individuals of the amphipod Gammarus spp. in a single-species assemblage and (4) 250
Theodoxus + 25 Gammarus in a "both grazers present" treatment. The grazer treatments corresponded to $\sim 1 \mathrm{~g}$ shell-free dry mass per mesocosm, equivalent to natural levels of shell-free biomass of grazers in the sampling area (Råberg and Kautsky 2007a). In the both grazers present treatment, the abundance ratio between Gammarus and Theodoxus (1:10) corresponded to a biomass ratio of $1: 1$ shell-free dry mass and was similar to the composition in the field (unpublished data). Natural populations of Gammarus, Palaemon and Theodoxus were collected on the same day as the experiment started and from the same area as the Fucus thalli. We picked experimental individuals at random, and for the grazers, we excluded individuals $<5 \mathrm{~mm}$. Ten per cent of the initial abundance of Gammarus was added twice during the experiment in order to compensate for an observed natural mortality of this species in summer (dead individuals floating at the surface).

Three weeks into the experiment (26 July), we visually estimated for each mesocosm the percentage cover of a thick growth of algae that developed on the water surface (colony forming diatoms). At the end of the experiment (after 31 days), a net bag (mesh size of $500 \mu \mathrm{m}$ ) was placed over each Fucus plant and attached algae (filamentous microalgae and cyanobacteria) were removed from the mesocosm sides. Water from the mesocosm was then filtered through a 300- $\mu \mathrm{m}$ sieve, retaining grazers and free-floating algae. All material was immediately frozen at $-20^{\circ} \mathrm{C}$. After defrosting, epiphytic algae on Fucus were easily removed by careful scraping, and all material was again sieved through a $300-\mu \mathrm{m}$ sieve. We sorted the algae into three categories: (1) "attached microalgae" consisting of cyanobacteria and filamentous uniseriate microalgae that grew both epiphytically on Fucus and on the mesocosm sides, (2) "ephemeral macroalgae" that grew epiphytically on Fucus and were sorted to species level (Ceramium tenuicorne, Cladophora glomerata, Dictyosiphon foeniculaceus, Pyliaella littoralis and Ulva spp.) and (3) "colony forming diatoms" that grew free floating in the mesocosms (mainly of the genus Melosira). The diatom colonies disintegrated during freezing into smaller fragments which easily passed through the second sieving. The colony forming diatoms were therefore obtained by allowing the water that passed through the sieve to settle for 2 days; the supernatant was then aspirated and filtered through grade 595 $\frac{1}{2}$ filters (mesh size 4-7 $\mu \mathrm{m}$ ). All algae and invertebrates were dried at 80 and $60^{\circ} \mathrm{C}$, respectively, for 3 days. Biomass of the ephemeral macroalgae, which only grew on the Fucus, was recalculated to grams of dry mass per $100 \mathrm{~g}$ dry mass of Fucus.

Experimental effects on the biomass of the canopy forming diatoms, attached microalgae and ephemeral macroalgae, and the numbers of the added grazers (Theodoxus and Gammarus) and alternative prey (other 
invertebrate species: small gastropods, isopods and copepods) were analysed with factorial ANOVAs, with omnivory and grazer treatments as fixed factors and the block factor as main random effect. Predation effects on Gammarus and Theodoxus were only tested for grazer treatments where the specific grazer was added. Data were square root transformed if necessary to meet the assumptions of homogeneous variances. We analysed the diversity of ephemeral macroalgae expressed as the Shannon Wiener index using a Generalized linear model with a log-link function (Wald statistic), since the distribution did not fit the normal distribution well, even after transformations. The block factor was removed from the statistical models where block $P$-values $>0.50$. Experimental effects on the species composition of macroalgae were analysed with a MANOVA. For algal variables with significant grazer effects (in ANOVA), we calculated effect sizes $\left(\eta^{2}\right)$ for planned comparisons to test the relative strengths of grazer presence (grazer present or not) and grazer complementarity (Theodoxus vs Gammarus; both grazers present vs only Theodoxus or only Gammarus). For variables with significant omnivore effects, we calculated effects sizes $\left(h^{2}\right)$ for planned contrasts to test the relative strength of direct and indirect effects of omnivore presence (omnivore effects in grazer treatments without and with Gammarus spp., respectively).

There are possible artifacts associated with using Fucus thalli as substrate, both regarding the behaviour of the omnivore and the grazers, and from scaling macroalgal biomass to the weight of the Fucus thallus. (1) Consumers strongly prefer the ephemeral micro- and macroalgae compared to the leathery Fucus thallus (Orav-Kotta and Kotta 2004), but when food is scarce consumers may start to feed also on Fucus (Hemmi et al. 2004). (2) In grazerfree conditions, strong overgrowth may hamper the growth of Fucus or cause degeneration of the tissue. (3) Treatments with strong grazing may promote Fucus growth by decreasing competition from epiphytic algae (Råberg and Kautsky 2008). We did not monitor the growth of each Fucus individual, but we tested for and found no systematic differences in Fucus biomass between treatments at the end of the experiment (no significant differences in dry weight between treatments-data not shown). Since the selection of Fucus thallus for the mesocosms were random, this indicates that there was no excessive growth or consumption in any treatment. We found no bite marks on Fucus, suggesting direct grazing was minimal (e.g. Hemmi et al. 2004). We also observed no degenerating Fucus thallus during the experiment. Furthermore, there was plenty of alternative algal prey during the experiment. No treatment combinations were completely devoid of micro- or macroalgae. We also tested experimental effects on ephemeral macroalgae without scaling for Fucus biomass, and this did not affect the results (not shown).

\section{Results}

Palaemon had strong effects on the composition of the herbivore community by preying on Gammarus, but not Theodoxus (Fig. 2). Palaemon suppressed Gammarus abundance by 72 and $79 \%$ in the both grazer present and Gammarus grazer treatments, respectively (Fig. 2a) (main effect of omnivore presence: $F_{1,12}=61.87, P<0.001$ ), but had no effect on Theodoxus abundance in any of the grazer treatments (Fig. 2b) (main effect of Palaemon presence: $\left.F_{1,12}=2.10, P=0.17\right)$. In the absence of Palaemon, Gammarus abundance increased from initial densities, which depended on the development of new recruits (size $<3 \mathrm{~mm}$ ), while Theodoxus densities remained unchanged. Thus, Gammarus populations thrived with high population growth rates, whereas Theodoxus populations survived with low rates of recruitment (as expected from their turnover rate). Additionally, numerous alternative prey were present in the mesocosms, consisting of copepods, small gastropods (Hydrobia spp.) and isopods (Idotea spp.) that either arrived with the water supply or were associated with the Fucus thallus (Fig. 2c). Palaemon presence significantly decreased abundances of alternative prey, as the total abundance of alternative prey was 1.8 times as high in mesocosms without Palaemon (numbers without Palaemon: $128.5 \pm 16.9$; numbers with Palaemon: $71.2 \pm 11.2$; average per mesocosm \pm SE; Table 1, Fig. 2c).

Grazer presence controlled the development of colony forming diatoms independent of the presence of Palaemon (Tables 1 and 2). In the treatments without grazers, diatoms (mainly of the genus Melosira) formed dense floating mats in the mesocosms (Supplement 1), and the biomass was 2.5 times higher compared to the average in treatments with grazers present, both with and without Palaemon (Fig. 3a). Grazer presence also led to a strong decrease in the biomass of attached microalgae (uniseriate green algae: Punctaria tenuissima, Mougeotia spp. and Ulothrix spp.; and cyanobacteria), which grew both on the sides and bottom of the mesocosm and epiphytic on the Fucus (Fig. 3b, Tables 1 and 2). Presence of Theodoxus (both in the single species and the both grazer present treatments) suppressed the biomass of attached microalgae by half compared to the Gammarus treatment (Fig. 3b, Table 2), indicating that Theodoxus was a much more effective grazer on attached microalgae than Gammarus. There were no significant effects of Palaemon on colony forming diatoms or attached microalgae (Table 1), indicating that Palaemon did not consume microalgae. 

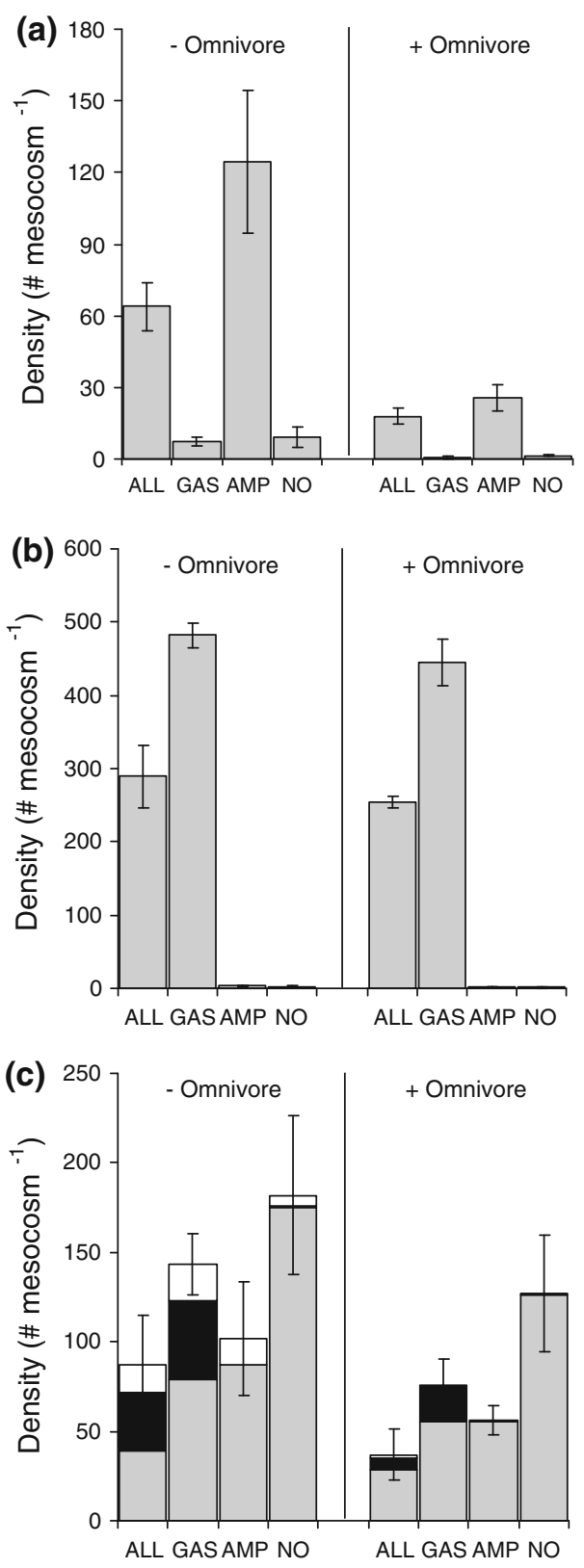

Fig. 2 Density of grazers in outdoor mesocosms after 31 days depending on the grazer identity treatment and the presence or absence of the omnivorous shrimp Palaemon; a the amphipod Gammarus spp., b the gastropod Theodoxus and c alternative prey: grey bars $=$ copepods, black bars $=$ small gastropods, white bars $=$ isopods. Grazer treatments: ALL = adding both Theodoxus (250 ind.) and Gammarus (25 ind.), GAS = adding Theodoxus (500 ind.), $\mathrm{AMP}=$ adding Gammarus $(50$ ind.), $\mathrm{NO}=$ no grazers added. Means \pm SE

The grazer treatments had significant effects on the total biomass of all ephemeral macroalgae (Table 1). In contrast to attached microalgae, Gammarus presence suppressed the macroalgal biomass by more than half compared to the Theodoxus treatment (Fig. 3c, Table 2), indicating strong effects of grazer identity on epiphytic micro- and macroalgae. Although Gammarus grazed significantly on macroalgae, in general grazer presence had a significantly positive effect on macroalgae compared to the no grazer treatments (Table 2), probably due to high loads both of colonial and attached filamentous microalgae outcompeting the macroalgae in the absence of grazers. Accordingly, in the treatments without grazers, there was a significant negative correlation between the cover of colonial microalgae and the biomass of the dominating ephemeral macroalgae, Pylaiella littoralis (Pearson product moment correlation, $\left.r=-0.73, t_{8}=2.8, p=0.026\right)$.

There were no significant omnivore (Palaemon) effects on the total biomass of ephemeral macroalgae (Fig. 3c, Table 1). However, there was a significant interaction effect between the omnivore and grazer treatments both on the community composition of ephemeral macroalgae (significant MANOVA effect for the interaction between omnivore presence and grazer identity: $F_{10,80}=3.45$, $P<0.01$; Fig. 3c) and macroalgal diversity (expressed as Shannon Wiener Diversity; Fig. 3d; Table 1). Palaemon grazed significantly on green algae, suppressing the biomass of Cladophora glomerata and Ulva spp. in the Theodoxus treatment (Supplements 2 and 3, Table 3). Palaemon also had a positive effect on Pylaiella littoralis in both treatments without Gammarus. Presence of Palaemon thereby suppressed diversity of ephemeral macroalgae in the Theodoxus treatment by increasing the dominance of the brown alga Pylaiella littoralis (reducing the evenness of species diversity). Indirect effects of Palaemon were restricted to the red algae Ceramium tenuicorne, which was positively affected by Palaemon, but only when both Theodoxus and Gammarus were present in the treatment (Supplements 2 and 3, Table 3). Thus, we found direct negative effects of omnivore grazing on green macroalgae that affected the general diversity of the macroalgal community, and indirect positive effects restricted to one species of red macroalgae.

\section{Discussion}

In our experiment, the omnivorous shrimp Palaemon had significant direct effects on the composition of both the herbivore and the algal trophic levels by effectively consuming Gammarus and ephemeral green macroalgae. Palaemon decreased the density of the amphipod Gammarus strongly but had no effect on gastropod abundance (Theodoxus). In the absence of Gammarus, Palaemon also had significant effects on macroalgal community composition. By reducing green macroalgae, Palaemon did not suppress the total production of ephemeral macroalgae, but strongly promoted the dominance of brown algae (Pylaiella littoralis) and concomitantly reduced species diversity. 
Table 1 General and generalized linear model results (presented by the F and Wald statistic, respectively) for the abundance of alternative prey (copepods, small gastropods and isopods) and micro- and macroalgae in response to different grazer treatments with and without omnivores

\begin{tabular}{|c|c|c|c|c|c|c|c|c|c|c|c|}
\hline \multirow[b]{2}{*}{ Source } & \multicolumn{3}{|c|}{$\begin{array}{l}\text { Alternative prey } \\
\text { (number) }\end{array}$} & \multicolumn{2}{|c|}{$\begin{array}{l}\text { Colony forming } \\
\text { diatoms }(\mathrm{dw})\end{array}$} & \multicolumn{2}{|c|}{$\begin{array}{l}\text { Attached } \\
\text { microalgae (dw) }\end{array}$} & \multicolumn{2}{|c|}{$\begin{array}{l}\text { Ephemeral } \\
\text { macroalgae (dw) }\end{array}$} & \multicolumn{2}{|c|}{$\begin{array}{l}\text { Species diversity } \\
\left(\mathrm{H}^{\prime}\right) \text { : macroalgae }\end{array}$} \\
\hline & $d f$ & $F$ & $P$ & $F$ & $P$ & $F$ & $P$ & $F$ & $P$ & Wald & $P$ \\
\hline Omnivore presence $(\mathrm{O})$ & 1 & 9.24 & 0.005 & 1.02 & 0.320 & 0.04 & 0.836 & 2.45 & 0.129 & 4.99 & 0.026 \\
\hline Grazer identity $(\mathrm{G})$ & 3 & 5.68 & 0.004 & 16.10 & 0.000 & 28.44 & 0.000 & 8.88 & 0.000 & 0.19 & 0.911 \\
\hline $\mathrm{O} \times \mathrm{G}$ & 3 & 0.20 & 0.895 & 2.60 & 0.070 & 0.60 & 0.621 & 0.80 & 0.504 & 7.72 & 0.021 \\
\hline Block & 4 & 2.38 & 0.077 & - & - & - & - & 2.59 & 0.059 & 6.91 & 0.141 \\
\hline Error & 28 & & & & & & & & & & \\
\hline
\end{tabular}

If the block factor appeared $P>0.50$, it was removed from the statistical model

Table 2 Statistical results and effect sizes $\left(\eta^{2}\right)$ from planned comparisons of grazer effects within the general linear models describing experimental effects on the biomass of micro- and macroalgae

\begin{tabular}{|c|c|c|c|c|c|c|c|c|c|c|}
\hline \multirow[b]{2}{*}{ Effect } & \multicolumn{4}{|c|}{ Colony forming diatoms } & \multicolumn{3}{|c|}{ Attached microalgae } & \multicolumn{3}{|c|}{ Ephemeral macroalgae } \\
\hline & $d f$ & $F$ & $P$ & $\eta^{2}$ & $F$ & $P$ & $\eta^{2}$ & $F$ & $P$ & $\eta^{2}$ \\
\hline \multicolumn{11}{|l|}{ Grazer presence } \\
\hline $\begin{array}{l}\text { ALL and GAS and AMP vs NO } \\
\text { Grazer complementarity }\end{array}$ & 1 & 45.68 & $<0.001$ & -0.52 & 58.89 & $<0.001$ & -0.50 & 5.30 & 0.029 & +0.08 \\
\hline GAS vs AMP & 1 & 0.71 & 0.406 & 0.01 & 13.56 & 0.001 & -0.11 & 12.91 & 0.001 & +0.19 \\
\hline ALL vs GAS and AMP & 1 & 1.92 & 0.176 & 0.02 & 12.87 & 0.001 & -0.26 & 8.43 & 0.007 & -0.13 \\
\hline ALL vs AMP & 1 & 2.63 & 0.115 & 0.03 & 24.48 & $<0.001$ & -0.21 & 0.52 & 0.479 & 0.01 \\
\hline ALL vs GAS & 1 & 0.61 & 0.441 & 0.01 & 1.60 & 0.215 & 0.01 & 18.58 & $<0.001$ & -0.28 \\
\hline
\end{tabular}

Signs indicate direction of significant grazer effects

For general GLM results, see Table 1

Grazer treatments: ALL adding both Theodoxus and Gammarus, GAS adding Theodoxus, AMP adding Gammarus, NO no grazers added

Alternative prey was present in all treatment combinations suggesting that experimental effects were not caused by experimentally induced starving. Thus, we demonstrate that vertical food web effects of an omnivore depend on the functional composition of grazers, where the relative amount of consumption on the grazer and algal trophic levels by Palaemon depended on the availability of amphipod prey.

We documented no significant indirect predation effects by Palaemon on total primary biomass in the experiment. However, there was a significant positive effect of Palaemon presence on the red algae Ceramium tenuicorne when both grazers were present, which may have been caused by Palaemon predation. Thus, we demonstrated a species cascade from including the omnivorous shrimp on one macroalgal species, but no community-wide trophic cascade on the total biomass of the macroalgal community. Palaemon decreased the abundance of Gammarus by $80 \%$ and Gammarus, in turn, decreased the total biomass of ephemeral macroalgae to a third. This indicates potential for a strong reciprocal relationship between these three groups. This is supported by other experiments in which
Palaemon, through strong predation on Gammarus locusta, induced trophic cascades that led to an increase in macroalgal biomass up to seven times, when allowed to become the dominant predator (Moksnes et al. 2008; Persson et al. 2008). However, in our experiment, direct grazing effects by Palaemon on green macroalgae determined the macroalgae community in the grazer treatment without Gammarus. This indicates that Palaemon may have suppressed the development of a community-wide trophic cascade by grazing on green macroalgae when the abundance of Gammarus decreased (no change in the total biomass of ephemeral macroalgae in the treatments with Gammarus). We found no direct grazing effects of Palaemon on C. tenuicorne, which may explain the significant positive indirect effects of Palaemon on this species (significant species cascade). Interestingly, isotope analyses show that Palaemon can modify their food preferences, consuming mainly grazers in some areas and mainly ephemeral macroalgae in other areas, perhaps depending on the availability of smaller sizes of mesograzer prey (Jephson et al. 2008; Persson et al. 2008). Thus, our experiment supports the role of omnivory in suppressing 

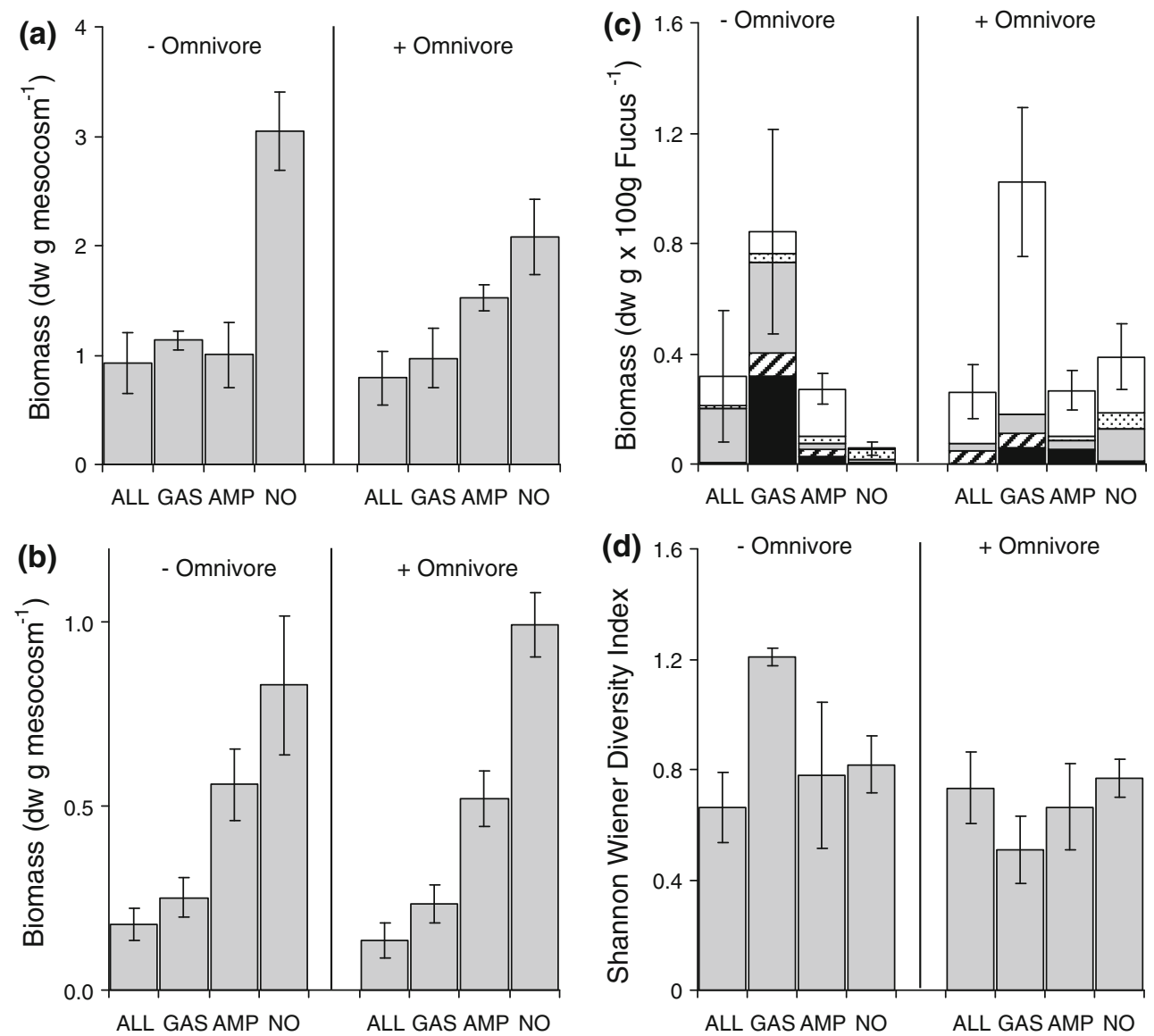

Fig. 3 Abundance of algae in outdoor mesocosms after 31 days depending on the grazer treatment and the presence or absence of the omnivorous shrimp Palaemon; a biomass of colony forming diatoms in water, $\mathbf{b}$ biomass of attached microalgae, $\mathbf{c}$ biomass of ephemeral macroalgae: white bars = Pylaiella littoralis; dotted bars = Ulva spp.; grey bars $=$ Dictyosiphon foeniculaceus; striped bars $=$ Ceramium

tenuicorne; black bars $=$ Cladophora glomerata, $\mathbf{d}$ species diversity of ephemeral macroalgae. Grazer treatments: ALL = adding both Theodoxus (250 ind.) and Gammarus (25 ind.), GAS = adding Theodoxus (500 ind.), $\mathrm{AMP}=$ adding Gammarus $(50$ ind.), $\mathrm{NO}=$ no grazers added. Means \pm SE

Table 3 Statistical results and effect sizes $\left(\eta^{2}\right)$ from planned comparisons of direct and indirect effects of Palaemon spp. within the general linear models describing experimental effects on the biomass of individual macroalgal species

\begin{tabular}{|c|c|c|c|c|c|c|c|c|c|c|c|c|c|c|c|c|}
\hline \multirow[t]{2}{*}{ Omnivore effects } & \multicolumn{4}{|c|}{ Ceramium tenuicorne } & \multicolumn{3}{|c|}{ Cladophora glomerata } & \multicolumn{3}{|c|}{ Dictyosiphon foeniculaceus } & \multicolumn{3}{|c|}{ Pyliaella littoralis } & \multicolumn{3}{|c|}{ Ulva spp. } \\
\hline & $d f$ & $F$ & $P$ & $\dot{\eta}^{2}$ & $F$ & $P$ & $\eta^{2}$ & $F$ & $P$ & $\eta^{2}$ & $F$ & $P$ & $\eta^{2}$ & $F$ & $P$ & $\eta^{2}$ \\
\hline \multicolumn{17}{|l|}{ Direct consumption } \\
\hline NO (No Grazer) & 1 & 0.21 & 0.653 & 0.00 & 0.12 & 0.728 & 0.00 & 0.37 & 0.546 & 0.01 & 10.86 & 0.003 & +0.11 & 0.40 & 0.533 & 0.01 \\
\hline GAS (Theodoxus) & 1 & 1.58 & 0.220 & 0.02 & 13.67 & 0.001 & -0.17 & 1.88 & 0.182 & 0.05 & 25.95 & $<0.001$ & +0.25 & 6.69 & 0.015 & -0.13 \\
\hline \multicolumn{17}{|l|}{ Indirect predation } \\
\hline AMP (Gammarus) & 1 & 1.55 & 0.223 & 0.02 & 0.19 & 0.670 & 0.00 & 0.24 & 0.630 & 0.01 & 0.57 & 0.458 & 0.01 & 0.38 & 0.545 & 0.01 \\
\hline ALL (both Grazers) & 1 & 8.54 & 0.007 & +0.12 & 0.00 & 0.998 & 0.00 & 0.82 & 0.374 & 0.02 & 1.04 & 0.316 & 0.01 & 0.40 & 0.533 & 0.01 \\
\hline
\end{tabular}

Signs indicate the direction of significant omnivore effects

For general GLM results, see Supplement 2

Direct effects = effects of Palaemon presence in grazer identity treatments without Gammarus spp. (GAS and NO). Indirect effects $=$ effects of Palaemon presence in grazer identity treatments with Gammarus spp. (AMP and ALL)

trophic cascades when omnivores compensate for their predation effects on herbivores through their ability to graze on primary producers.
In general, herbivores benefit producer evenness in marine systems (Hillebrand 2003; Hillebrand et al. 2007). However, the broad interpretation generally applies to 
systems with one strong dominant species that is sensitive to grazing (e.g. Altieri et al. 2009), whereas in our study system, grazing instead promoted dominance by one macroalgal species (Pylaiella littoralis). Dominance determines the distribution of traits in a community, and species evenness may therefore have a stronger effect on community function than species richness (which determines the number of traits) (Hillebrand et al. 2008). In our experiment, there was no relation between species dominance and the accumulation of macroalgal community biomass. However, species evenness of natural macroalgal communities tend to increase production but not necessarily standing biomass (Altieri et al. 2009; Arenas et al. 2009), which indicate that the documented interaction between grazers and macroalgae dominance in our experiment may have significant long-term effects on the function of the community. Like many brown algae, $P$. littoralis exudes toxic substances that may deter herbivores (Råberg et al. 2005), and this may explain the dominance of $P$. littoralis in treatments with a high grazing pressure. Although the omnivore Palaemon demonstrated the same complementary grazing function on macroalgal structure as the mesograzer Gammarus, Palaemon promoted P.littoralis dominance even more. This can be seen in the uncontrolled increase in macroalgal biomass in the omnivore treatment without Gammarus, when P. littoralis escaped top-down control. Similar positive effects were demonstrated on brown algae by omnivorous benthic fish when the main mesograzer amphipod (Ampithoe longimana) was removed (Duffy and Hay 2000). Our results fit simple model predictions stating that a herbivore must exploit the common resource with a higher efficiency than an omnivore to enable coexistence in an omnivorous three-level food web (Polis and Holt 1992; Diehl 1993).

The degree of diet overlap by gastropod and crustacean grazers determined the structure of the algal community. Our study confirms earlier results that grazer identity determines algal community composition and production (Råberg and Kautsky 2007b): the gastropod Theodoxus grazed more on microalgae, and the amphipod Gammarus controlled macroalgae. There were no significant differences in production of microalgae between the both grazer present and the Theodoxus treatment, and no significant differences in production of macroalgae between the both grazer present and the Gammarus treatment. This demonstrates the strong species identity effects on grazing rates predicted by theoretical models (Symstad et al. 1998; Loreau and Hector 2001). However, both functional groups of mesograzers were needed to control both the macro- and microalgal production, demonstrating complementarity effects on top-down control in aquatic systems by resource partitioning between grazer groups shown by other studies (Duffy et al. 2003; Råberg and Kautsky 2007b). In absence of both functional groups of mesograzers, a thick layer of colonial microalgae developed on the surface of the mesocosms. This phenomenon is common in sheltered bays in the study area, and our results support that idea that some of the variation in natural algal blooms can be explained by different grazing rates (Eriksson et al. 2009). Moreover, our results indicated a strong trade-off between palatability and the ability to respond to resource fluctuations between the functional groups of mesograzers. For example, Theodoxus abundance was constant throughout the experiment, and we detected no significant predation effects by the omnivore and no new recruitment into the mesocosms. Gammarus, on the other hand, was heavily decimated by omnivore predation, but also showed a strong recruitment of new individuals into the mesocosms. Thus, Theodoxus is a 'static grazer' with little capacity to quickly change population size in response to favourable changes in the environment, but at the same time comparably resistant to predation. Gammarus, on the other hand, is more a 'dynamic' grazer with the capacity to quickly change population size, but was comparably sensitive to predation.

Our experiment demonstrates two properties of food webs that prevent community level trophic cascades: (1) strong direct effects by omnivores on more than one trophic levels and (2) a diversified prey community where at least one dominant grazer is tolerant to predation. The ability to feed on alternative prey makes omnivores less dependent on fluctuations in single prey populations, which promote persistence and may intensify top-down control (Polis and Strong 1996; Eubanks and Denno 1999). In some systems, strong top-down control by omnivores also translates to strong trophic cascades on plant or algal biomass, e.g. as demonstrated in salt marsh and seagrass ecosystems (Ho and Pennings 2008; Moksnes et al. 2008). In both the salt marsh and seagrass example, the omnivore induced a trophic cascade because it fed selectively on the main herbivore rather than plants or algae when both where available (Ho and Pennings 2008; Moksnes et al. 2008). Moreover, both studies also present species cascades involving one major herbivore on one plant or algal species only. In our system, functional complementarity at both the grazer (amphipods and gastropods) and algal (micro-/ macroalgae) trophic levels compensated for decreases in the other group. Only when both grazer groups were removed from the system, the total biomass of micro- and macroalgae together increased. Thus, while species cascades may be common in food webs, community level trophic cascades are probably rare in natural communities due to omnivory and within trophic level trait diversity (Polis 1999).

The linking of reduction in top-predators to massive increases of mesopredator populations is common in exploited ecosystems (Eriksson et al. 2009; Ritchie and 
Johnson 2009). The impact of mesopredator-release events depends on food web connectivity, where a high number of weak trophic links should decrease the strength of topdown control and reduce the probability of trophic cascades (Dunne et al. 2002; Neutel et al. 2002; Duffy et al. 2007). Our results show that even though omnivores have links to more than one trophic level, the links may be strong and switch in magnitude depending on availability and functional composition of the prey community. For example, Moksnes et al. (2008) suggested that increases in $P$. elegans from large scale decreases in apex predators (Gadhus morrhua-cod) have suppressed mesograzer abundances (mainly amphipods) and thereby indirectly contributed to increases in macroalgal production in the coastal zone of the Skagerrak (North Sea). In our study area (the Baltic Sea), substantial mesopredator release events of small-bodied fish have reduced grazing rates, and thereby dramatically increased local biomass production of ephemeral micro- and macroalgae (Eriksson et al. 2009; Sieben et al. 2011). However, the results of the present study suggested that the main impact caused by the presence of Palaemon was a decrease in macroalgal diversity, because Palaemon was able to include filamentous algae in its diet when palatable grazers decrease. Thus, to predict effects of changing abundances of omnivores, we need to acknowledge that omnivores may have deep vertical effects in food webs by links to several trophic levels. This specifically calls for incorporating properties of the food web, which determine the dynamics between indirect and direct effects of omnivores, such as interactions between the functional diversity on adjacent trophic levels and palatability of prey populations.

Acknowledgments We thank Susanne Govella and the crew at Askö Laboratory for valuable assistance in the field, and Birte Matthiessen, Jim Coyer and two anonymous reviewers for valuable comments on an earlier draft of the manuscript. The research was supported by a grant from the Swedish Research Council for Environment, Agricultural Sciences and Spatial Planning, Formas, through contract 1373702 (BKE).

Open Access This article is distributed under the terms of the Creative Commons Attribution Noncommercial License which permits any noncommercial use, distribution, and reproduction in any medium, provided the original author(s) and source are credited.

\section{References}

Altieri AH, Trussell GC, Ewanchuk PJ, Bernatchez G, Bracken MES (2009) Consumers control diversity and functioning of a natural marine ecosystem. Plos One 4:1-6

Arenas F, Rey F, Pinto IS (2009) Diversity effects beyond species richness: evidence from intertidal macroalgal assemblages. Mar Ecol Prog Ser 381:99-108
Bruno JF, O'Connor MI (2005) Cascading effects of predator diversity and omnivory in a marine food web. Ecol Lett 8:1048-1056

Casini M, Lovgren J, Hjelm J, Cardinale M, Molinero JC, Kornilovs G (2008) Multi-level trophic cascades in a heavily exploited open marine ecosystem. Proc R Soc B Biol Sci 275:1793-1801

Daskalov GM, Grishin AN, Rodionov S, Mihneva V (2007) Trophic cascades triggered by overfishing reveal possible mechanisms of ecosystem regime shifts. Proc Natl Acad Sci USA 104:1051810523

Diehl S (1993) Relative consumer sizes and the strengths of direct and indirect interactions in omnivorous feeding relationships. Oikos 68:151-157

Duffy JE, Hay ME (2000) Strong impacts of grazing amphipods on the organization of a benthic community. Ecol Monogr 70:237-263

Duffy JE, Richardson JP, Canuel EA (2003) Grazer diversity effects on ecosystem functioning in seagrass beds. Ecol Lett 6:637-645

Duffy JE, Cardinale BJ, France KE, McIntyre PB, Thebault E, Loreau M (2007) The functional role of biodiversity in ecosystems: incorporating trophic complexity. Ecol Lett 10:522-538

Dunne JA, Williams RJ, Martinez ND (2002) Network structure and biodiversity loss in food webs: robustness increases with connectance. Ecol Lett 5:558-567

Eriksson BK, Rubach A, Hillebrand H (2006) Biotic habitat complexity controls species diversity and nutrient effects on net biomass production. Ecology 87:246-254

Eriksson BK, Ljunggren L, Sandström A, Johansson G, Mattila J, Rubach A, Råberg S, Snickars M (2009) Declines in predatory fish promote bloom-forming macroalgae. Ecol Appl 19:19751988

Eubanks MD, Denno RF (1999) The ecological consequences of variation in plants and prey for an omnivorous insect. Ecology 80:1253-1266

Fagan WF (1997) Omnivory as a stabilizing feature of natural communities. Am Nat 150:554-567

Frank KT, Petrie B, Choi JS, Leggett WC (2005) Trophic cascades in a formerly cod-dominated ecosystem. Science 308:1621-1623

Gruner DS, Smith JE, Seabloom EW, Sandin SA, Ngai JT, Hillebrand H, Harpole WS, Elser JJ, Cleland EE, Bracken MES, Borer ET, Bolker BM (2008) A cross-system synthesis of consumer and nutrient resource control on producer biomass. Ecol Lett 11:740-755

Heithaus MR, Frid A, Wirsing AJ, Worm B (2008) Predicting ecological consequences of marine top predator declines. Trends Ecol Evol 23:202-210

Hemmi A, Honkanen T, Jormalainen V (2004) Inducible resistance to herbivory in Fucus vesiculosus-duration, spreading and variation with nutrient availability. Mar Ecol Prog Ser 273:109-120

Hillebrand H (2003) Opposing effects of grazing and nutrients on diversity. Oikos 100:592-600

Hillebrand H, Gruner DS, Borer ET, Bracken MES, Cleland EE, Elser JJ, Harpole WS, Ngai JT, Seabloom EW, Shurin JB, Smith JE (2007) Consumer versus resource control of producer diversity depends on ecosystem type and producer community structure. Proc Natl Acad Sci USA 104:10904-10909

Hillebrand H, Bennett DM, Cadotte MW (2008) Consequences of dominance: a review of evenness effects on local and regional ecosystem processes. Ecology 89:1510-1520

Ho CK, Pennings SC (2008) Consequences of omnivory for trophic interactions on a salt marsh shrub. Ecology 89:1714-1722

Jephson T, Nystrom P, Moksnes PO, Baden SP (2008) Trophic interactions in Zostera marina beds along the Swedish coast. Mar Ecol Prog Ser 369:63-76

Kinne O (1960) Gammarus Salinus-Einige Daten Über Den Umwelt-Einfluss Auf Wachstum, Häutungsfolge, Herzfrequenz Und Eientwicklungsdauer. Crustaceana 1:208-217 
Kirkegaard J (2006) Life history, growth and production of Theodoxus fluviatilis in Lake Esrom, Denmark. Limnologica 36:26-41

Loreau M, Hector A (2001) Partitioning selection and complementarity in biodiversity experiments. Nature 412:72-76

Lotze HK, Worm B, Sommer U (2001) Strong bottom-up and topdown control of early life stages of macroalgae. Limnol Oceanogr 46:749-757

Matthiessen B, Gamfeldt L, Jonsson PR, Hillebrand H (2007) Effects of grazer richness and composition on algal biomass in a closed and open marine system. Ecology 88:178-187

McCann K, Hastings A, Huxel GR (1998) Weak trophic interactions and the balance of nature. Nature 395:794-798

Moksnes P-O, Gullstrom M, Tryman K, Baden S (2008) Trophic cascades in a temperate seagrass community. Oikos 117:763-777

Myers RA, Baum JK, Shepherd TD, Powers SP, Peterson CH (2007) Cascading effects of the loss of apex predatory sharks from a coastal ocean. Science 315:1846-1850

Neutel AM, Heesterbeek JAP, de Ruiter PC (2002) Stability in real food webs: weak links in long loops. Science 296:1120-1123

Orav-Kotta H, Kotta J (2004) Food and habitat choice of the isopod Idotea baltica in the northeastern Baltic Sea. Hydrobiologia 514:79-85

Persson M, Andersson S, Baden S, Moksnes PO (2008) Trophic role of the omnivorous grass shrimp Palaemon elegans in a Swedish eelgrass system. Mar Ecol Prog Ser 371:203-212

Polis GA (1999) Why are parts of the world green? Multiple factors control productivity and the distribution of biomass. Oikos 86:3-15

Polis GA, Holt RD (1992) Intraguild predation-the dynamics of complex trophic interactions. Trends Ecol Evol 7:151-154
Polis GA, Strong DR (1996) Food web complexity and community dynamics. Am Nat 147:813-846

Råberg S, Kautsky L (2007a) A comparative biodiversity study of the associated fauna of perennial fucoids and filamentous algae. Estuar Coast Shelf Sci 73:249-258

Råberg S, Kautsky L (2007b) Consumers affect prey biomass and diversity through resource partitioning. Ecology 88:2468-2473

Råberg S, Kautsky L (2008) Grazer identity is crucial for facilitating growth of the perennial brown alga Fucus vesiculosus. Mar Ecol Prog Ser 361:111-118

Råberg S, Berger-Jonsson R, Björn A, Graneli E, Kautsky L (2005) Effects of Pilayella littoralis on Fucus vesiculosus recruitment: implications for community composition. Mar Ecol Prog Ser 289:131-139

Ritchie EG, Johnson CN (2009) Predator interactions, mesopredator release and biodiversity conservation. Ecol Lett 12:982-998

Scheffer M, Carpenter S, de Young B (2005) Cascading effects of overfishing marine systems. Trends Ecol Evol 20:579-581

Sieben K, Rippen AD, Eriksson BK (2011) Cascading effects from predator removal depend on resource availability in a benthic food web. Mar Biol 158. doi: 10.1007/s00227-010-1567-5

Symstad AJ, Tilman D, Willson J, Knops JMH (1998) Species loss and ecosystem functioning: effects of species identity and community composition. Oikos 81:389-397

Vasas V, Lancelot C, Rousseau V, Jordán F (2007) Eutrophication and overfishing in temperate nearshore pelagic food webs: a network perspective. Mar Ecol Prog Ser 336:1-14

Worm B, Myers RA (2003) Meta-analysis of cod-shrimp interactions reveals top-down control in oceanic food webs. Ecology $84: 162-173$ 